\title{
Welding Material Selection for a Specific Butt V-Weld by Means of Assisted Stress and Fatigue Calculations
}

\author{
Dijmărescu Maria-Cristina ${ }^{1,}$, Dijmărescu Manuela-Roxana ${ }^{2, b^{*}}$ \\ ${ }^{1}$ University POLITEHNICA of Bucharest, Materials Technology and Welding Department, \\ ${ }^{2}$ University POLITEHNICA of Bucharest, Manufacturing Engineering Department, \\ 313 Splaiul Independentei, 060042 Bucharest, Romania \\ acristina_dijmarescu@yahoo.com, ${ }^{b}$ manuela.dijmarescu@imst.pub.ro
}

Keywords: Welding material, Material selection, Butt V-weld joint, Weld stress, Weld fatigue

\begin{abstract}
When talking about welding joints, an important issue is choosing the proper welding material in order to comply with design requirements, if possible, without undertaking physical tests. The present research focuses on an assisted approach for the selection of the proper welding material for a specific butt V-weld by using the tools made available by the Autodesk Inventor software. The main elements taken into consideration for the research program are: identification of a number of suitable welding materials for the designed butt joint, assisted stress and fatigue resistance analysis of the weld joint for each possible welding material, record and interpretation of the results, selection of the welding material(s), making a weld sample for further physical testing and results comparison.
\end{abstract}

\section{Introduction}

When dealing with a high market demand for a certain product, the necessary time for its development process should be as short as possible. Today, a solution to this problem is provided by the assisted tools which can be used in the design process and due to which the subsequent manufacturing and testing activities are considerably shortened. For welded products, the design process includes, besides the classical design phases, the design of the welded joint; an activity which has as principal phases the selection of the weld groove and of the welding material. It is known that the welded structures have, in general, low fatigue strength. At the same time, it is true that not so many welded parts break, but the ones that do break do so because of fatigue cracking or corrosion fatigue [1], for this reason attention should be paid to the fatigue resistance of the welded joint when selecting the weld groove type and the welding material.

In time, various stress and fatigue resistance tests have been made by scientists in order to obtain a precise overview of the welded joints resistance [2-4] and the outputs of these results have been used as inputs in the design process and implemented in assisted tools. As a result, today, these tools help designers to make important decisions from this product development phase and to arrive faster at a certain desired solution.

In the following sections of this paper five possible welding materials will be analyzed by means of stress and fatigue strength compliance for a specific butt V-weld by using the weld tools available in Autodesk Inventor software.

\section{Initial data}

The welding materials considered for the analysis are: T $199 \mathrm{~L} \mathrm{R} \mathrm{C/M} 3, \mathrm{~T} 2312 \mathrm{~L} \mathrm{R} \mathrm{C/M} \mathrm{3,} \mathrm{T} 23$ 12 L P C/M 1, T 19123 L R C/M 3, T 19123 L P C/M 1 according to SR EN ISO 17633-A: 2010. These materials can be found in form of high-alloy, rutile MAG flux cored wire electrode and have the following common properties: excellent weldability, low spatter formation; slowly solidifying slag, operating temperature with dissimilar joints $300^{\circ} \mathrm{C}[5]$.

Their types, chemical composition and mechanical properties are shown in Tables 1 and 2, where it can be seen that the percentage of Carbon, Silicon, Phosphorus and Sulfur is identical for all five selected materials. 
Table 1. Type and chemical composition of the welding materials $[5,6]$.

\begin{tabular}{|c|c|c|c|c|c|c|c|c|c|c|}
\hline \multirow{2}{*}{ Alloy type } & \multirow{2}{*}{ Material grade } & \multicolumn{9}{|c|}{ Chemical composition [\%] } \\
\hline & & $\mathrm{C}$ & $\mathrm{Si}$ & $\mathrm{Mn}$ & $\mathrm{P}$ & $\mathrm{S}$ & $\mathrm{Ni}$ & $\mathrm{Cr}$ & Mo & $\mathrm{Cu}$ \\
\hline \multirow{3}{*}{$\begin{array}{l}\text { High-alloy - } \\
\text { stainless steel }\end{array}$} & T 199 L R C/M 3 & 0,04 & 0,8 & 1,5 & 0,04 & 0,03 & 9,5 & 19,5 & 0,3 & - \\
\hline & T 2312 L R C/M 3 & 0,04 & 0,8 & 2,5 & 0,04 & 0,03 & 13 & 23 & 0,5 & 0,5 \\
\hline & T $2312 \mathrm{~L} \mathrm{P} \mathrm{C/M} 1$ & 0,04 & 0,8 & 2,5 & 0,04 & 0,03 & 13 & 24 & 0,5 & 0,5 \\
\hline \multirow{2}{*}{$\begin{array}{l}\text { High-alloy - } \\
\text { creep resistant }\end{array}$} & T 19123 L R C/M 3 & 0,04 & 0,8 & 2,5 & 0,04 & 0,03 & 13 & 19 & 2,5 & 0,5 \\
\hline & T 19123 L P C/M 1 & 0,04 & 0,8 & 2,5 & 0,04 & 0,03 & 13 & 19 & 2,5 & - \\
\hline
\end{tabular}

Table 2. Type and mechanical properties of the welding materials [5, 6].

\begin{tabular}{|c|c|c|c|c|c|}
\hline \multirow[b]{2}{*}{ Alloy type } & \multirow[b]{2}{*}{ Material grade } & \multicolumn{4}{|c|}{ Mechanical properties } \\
\hline & & $\begin{array}{l}\text { Yield Strength, } \\
\mathrm{R}_{\mathrm{p} 0.2 \%}[\mathrm{MPa}]\end{array}$ & $\begin{array}{l}\text { Tensile strength, } \\
\mathrm{R}_{\mathrm{m}}[\mathrm{MPa}]\end{array}$ & $\begin{array}{c}\text { Elongation, } \\
\text { A5 [\%] }\end{array}$ & $\begin{array}{c}\text { Impact Energy } \\
{[\mathrm{J}]\left(0^{\circ} \mathrm{C}\right)}\end{array}$ \\
\hline \multirow{3}{*}{$\begin{array}{l}\text { High-alloy - } \\
\text { stainless steel }\end{array}$} & T 199 L R C/M 3 & 370 & 520 & 41 & 35 \\
\hline & T 2312 L R C/M 3 & 390 & 520 & 30 & - \\
\hline & T 2312 L P C/M 1 & 390 & 520 & 30 & 54 \\
\hline \multirow{2}{*}{$\begin{array}{l}\text { High-alloy - } \\
\text { creep resistant }\end{array}$} & T 19123 L R C/M 3 & 380 & 485 & 30 & 44 \\
\hline & T 19123 L P C/M 1 & 370 & 485 & 30 & 54 \\
\hline
\end{tabular}

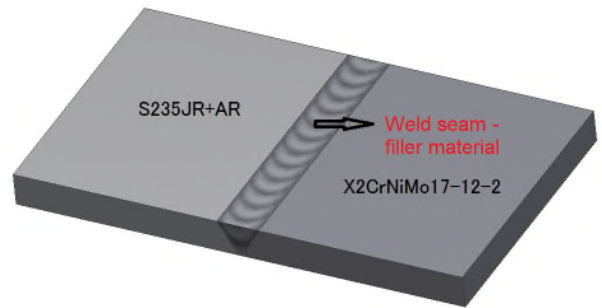

Fig. 1 Virtual 3D model of the future samples.

The static and fatigue design calculations shall be performed for a weld joint of two plates from different materials with an end butt weld (Fig. 1).

The groove type was selected in accordance to the rules from SR EN 9692/1 and its form and dimensions are presented in Fig. 2.

The base materials to be welded are S235JR+AR (SR EN 1002 -2:2004) and X2CrNiMo17-12-2 (SR EN 10028-7:2008). Their form is that of sheets with the dimensions of $120 \mathrm{~mm} \times 100 \mathrm{~mm} \times 15$ $\mathrm{mm}$.

In order to execute the calculations, the following inputs are necessary: normal force $\left(F_{n}\right)$, plate thickness (s), weld length (L) and the joint material properties, as shown in the above tables. The first three parameters (Fig. 3) used for the analysis of the weld seam are: $F_{n}=200000 \mathrm{~N}, \mathrm{~s}=15 \mathrm{~mm}, \mathrm{~L}=$ $120 \mathrm{~mm}$. Besides these parameters, a safety factor, $\mathrm{n}_{\mathrm{s}}=1,7$, will be considered.

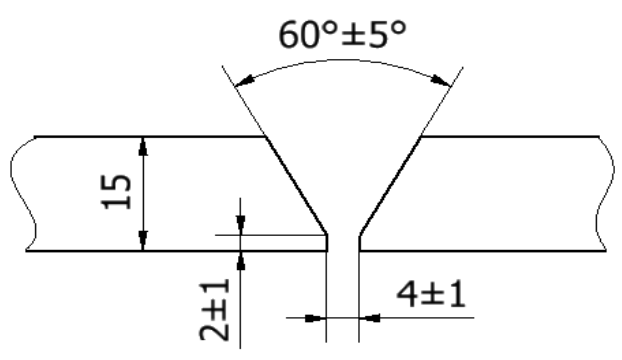

Fig. 2. Weld groove dimensions
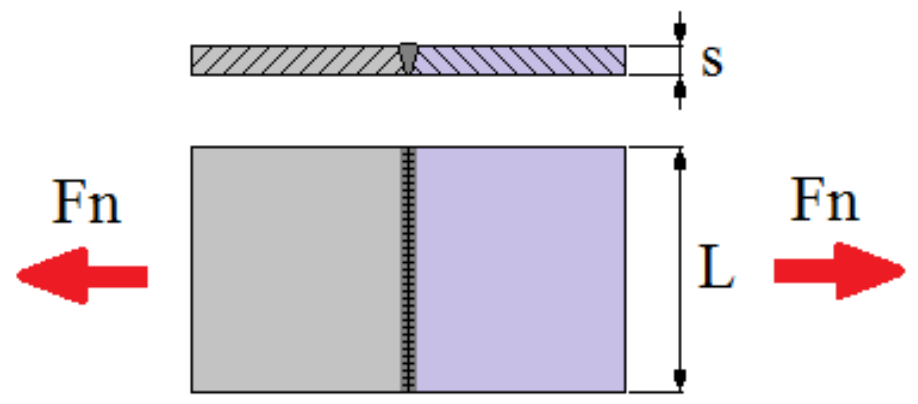

Fig. 3. Dimensions of the welded structure and applied loads 
For fatigue design calculations, the considered inputs will be:

$\rightarrow$ case 1: repeated normal force cycle $\left(\mathrm{F}_{\mathrm{n}}=100000 \mathrm{~N}\right)$, the number of considered cycles, $\mathrm{N}=100000$, and a required safety degree, $\mathrm{n}_{\mathrm{f}}=2,5$;

$\rightarrow$ case 2: fluctuated normal force cycles $\left(\mathrm{F}_{\mathrm{nmin}} \div \mathrm{F}_{\mathrm{nmax}}=10000 \div 100000 \mathrm{~N}\right), \mathrm{N}=100000$ cycles, $\mathrm{n}_{\mathrm{f}}=2,5$.

The fatigue design calculation method to be applied is Soderberg method (Eq. $1[1,7]$, Fig. 4).

$$
\left(\frac{\sigma_{a}}{\sigma_{m}}\right)+\left(\frac{\sigma_{m}}{\sigma_{y}}\right)=1
$$

where:

$\sigma_{a}-$ amplitude of normal stress [MPa];

$\sigma_{\theta}$ - endurance limit at the constant strength [MPa];

$\sigma_{m}-$ mean cycle stress $[\mathrm{MPa}]$;

$\sigma_{u}-$ ultimate tensile strength [MPa];

$\sigma_{y}-$ Yield tensile strength [MPa].

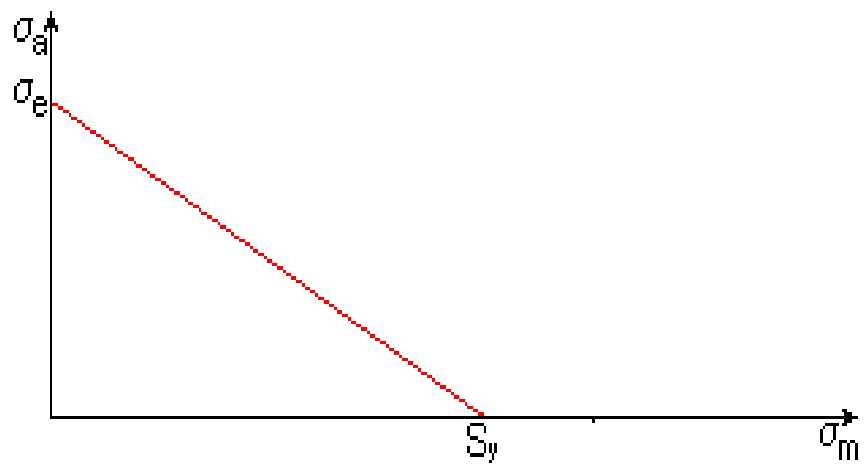

Fig. 4. Soderberg method chart [7].

\section{Data definition and calculations}

In order to perform the desired assisted weld static and fatigue design calculations, the following steps should be completed: $\rightarrow$ creation of the weld assembly parametric model (Fig. 1 ); $\rightarrow$ definition and assignation of the prescribed materials properties; $\rightarrow$ activation of the butt weld calculator and introduction of the desired inputs for the static stress calculation (Fn, s, L) in the specific fields (Fig. 5); $\rightarrow$ introduction of the fatigue design inputs for case 1 (Fig. 6) and case 2 (Fig. 7); $\rightarrow$ definition of the welding materials in order to be assigned to the calculations (Fig. 8); $\rightarrow$ performing the weld static and fatigue design calculations for all five welding materials.

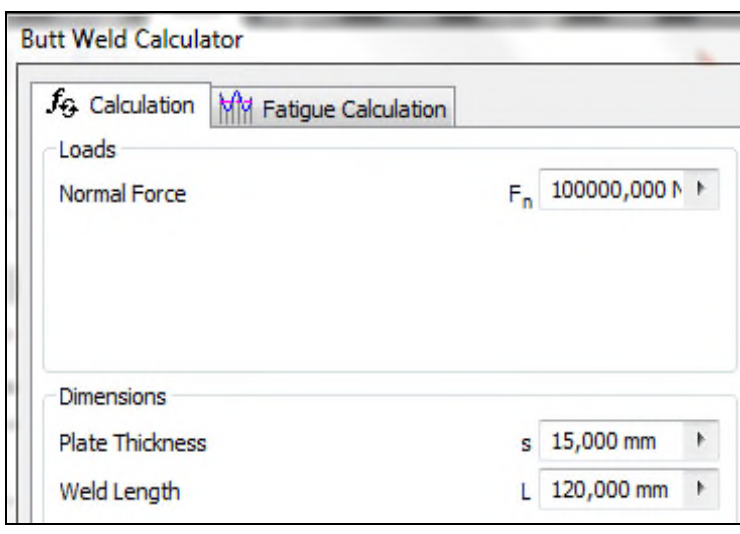

Fig. 5 Stress calculations input window.

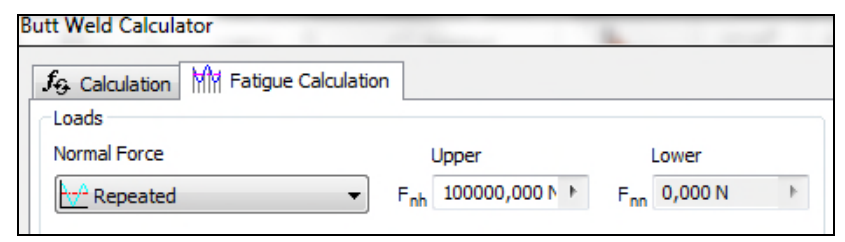

Fig. 6 Fatigue calculations input window - case 1.

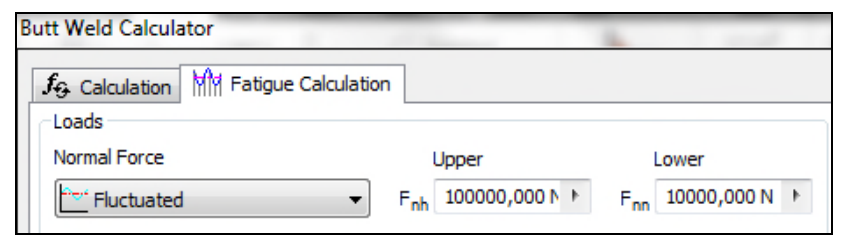

Fig. 7 Fatigue calculations input window - case 2. 


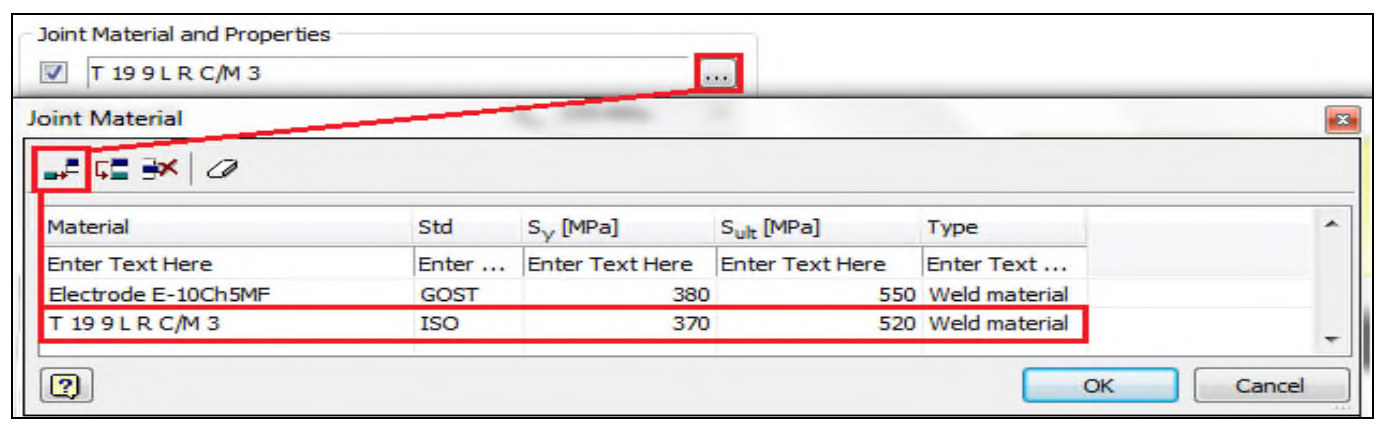

Fig. 8 Welding material definition window.

\section{Results and Discussion}

After performing the weld static and fatigue design calculations, the obtained results were registered in order to make an analysis and to choose the welding material(s) for the physical samples. The static calculations results are shown in Table 3 and the fatigue calculations are shown in Tables 4 - for calculation case 1 - and Table 5 - for calculation case 2 .

Table 3. Results of the static calculations $\left(\mathrm{F}_{\mathrm{n}}=100000 \mathrm{~N}, \mathrm{n}_{\mathrm{s}}=1,7\right)$.

\begin{tabular}{|l|c|c|c|c|c|}
\hline \multicolumn{1}{|c|}{ Welding material } & $\begin{array}{c}\text { T 19 9 L R } \\
\text { C/M 3 }\end{array}$ & $\begin{array}{c}\text { T 23 12 L } \\
\text { R C/M 3 }\end{array}$ & $\begin{array}{c}\text { T 23 12 L } \\
\text { P C/M 1 }\end{array}$ & $\begin{array}{c}\text { T 19 12 3 L } \\
\text { R C/M 3 }\end{array}$ & $\begin{array}{c}\text { T 19 12 3 L } \\
\text { P C/M 1 }\end{array}$ \\
\hline Allowable stress, $\sigma_{\sigma}[\mathrm{MPa}]$ & 217,65 & 229,41 & 229,41 & 223,53 & 217,65 \\
\hline Minimum plate thickness, $\mathrm{s}_{\min }[\mathrm{mm}]$ & 3,84 & 3,64 & 3,64 & 3,74 & 3,84 \\
\hline Minimum weld length, $\mathrm{L}_{\min }[\mathrm{mm}]$ & 30,64 & 29,07 & 29,07 & 29,83 & 30,64 \\
\hline Weld normal stress, $\sigma[\mathrm{MPa}]$ & 55,56 & 55,56 & 55,56 & 55,56 & 55,56 \\
\hline Maximum normal force, $\mathrm{F}_{\text {nmax }}[\mathrm{N}]$ & 391764,7 & 412941,1 & 412941,1 & 402352,9 & 391764,7 \\
\hline
\end{tabular}

For all five analyzed materials, the weld normal stress is smaller than the weld allowable stress, a fact that confirms the design compliance of the considered butt V-weld. The results show that the analyzed welding materials have a very close allowable stress limit - the materials with the minimum allowable stress are: T $199 \mathrm{~L} \mathrm{R} \mathrm{C/M} 3$ and T $19123 \mathrm{~L} \mathrm{P} \mathrm{C/M} 1\left(\sigma_{a}=217,65 \mathrm{MPa}\right)$; and the materials with the maximum allowable stress are: T $2312 \mathrm{~L} \mathrm{R} \mathrm{C/M} 3$ and T $2312 \mathrm{~L} \mathrm{R} \mathrm{C/M} 1$ $\left(\sigma_{a}=229,41 \mathrm{MPa}\right)$.

Table 4. Results of fatigue calculations (case 1: $\mathrm{F}_{\mathrm{n}}=100000 \mathrm{~N}, \mathrm{~N}=100000, \mathrm{n}_{\mathrm{f}}=2,5$ ).

\begin{tabular}{|l|c|c|c|c|c|}
\hline \multicolumn{1}{|c|}{ Welding material } & $\begin{array}{c}\text { T 19 9 L R } \\
\text { C/M 3 }\end{array}$ & $\begin{array}{c}\text { T 23 12 L } \\
\text { R C/M 3 }\end{array}$ & $\begin{array}{c}\text { T 23 12 L } \\
\text { P C/M 1 }\end{array}$ & $\begin{array}{c}\text { T 19 12 3 L } \\
\text { R C/M 3 }\end{array}$ & $\begin{array}{c}\text { T 19 12 3 L } \\
\text { P C/M 1 }\end{array}$ \\
\hline Corrected endurance limit, $\sigma_{\varepsilon}[\mathrm{MPa}]$ & 70,868 & 70,868 & 70,868 & 68,591 & 68,591 \\
\hline Finite-life fatigue limit, $\sigma_{\tilde{f}}[\mathrm{MPa}]$ & 125,119 & 125,119 & 125,119 & 119,614 & 119,614 \\
\hline Mean fatigue strength of the joint, $\sigma_{M}[\mathrm{MPa}]$ & 93,501 & 94,728 & 94,728 & 90,977 & 90,392 \\
\hline Amplitude of joint fatigue strength, $\sigma_{A}[\mathrm{MPa}]$ & 93,501 & 94,728 & 94,728 & 90,977 & 90,392 \\
\hline Mean cycle stress of the joint, $\sigma_{m}[\mathrm{MPa}]$ & 27,778 & 27,778 & 27,778 & 27,778 & 27,778 \\
\hline Cycle stress smplitude, $\sigma_{\Omega}[\mathrm{MPa}]$ & 27,778 & 27,778 & 27,778 & 27,778 & 27,778 \\
\hline Calculated safety degree, $\mathrm{n}_{\mathrm{c}}$ & 3,366 & 3,410 & 3,410 & 3,275 & 3,254 \\
\hline
\end{tabular}

Table 5. Results of fatigue calculations (case $2: F_{n}=10000 \div 100000 \mathrm{~N}, \mathrm{~N}=100000, \mathrm{n}_{\mathrm{f}}=2,5$ ).

\begin{tabular}{|l|c|c|c|c|c|}
\hline \multicolumn{1}{|c|}{ Welding material } & $\begin{array}{c}\text { T 19 9 L R } \\
\text { C/M 3 }\end{array}$ & $\begin{array}{c}\text { T 23 12 L } \\
\text { R C/M 3 }\end{array}$ & $\begin{array}{c}\text { T 23 12 L } \\
\text { P C/M 1 }\end{array}$ & $\begin{array}{c}\text { T 19 12 3 L } \\
\text { R C/M 3 }\end{array}$ & $\begin{array}{c}\text { T 19 12 3 L } \\
\text { P C/M 1 }\end{array}$ \\
\hline Corrected endurance limit, $\sigma_{\varepsilon}[\mathrm{MPa}]$ & 70,868 & 70,868 & 70,868 & 68,591 & 68,591 \\
\hline Finite-life fatigue limit, $\sigma_{f}[\mathrm{MPa}]$ & 125,119 & 125,119 & 125,119 & 119,614 & 119,614 \\
\hline Mean fatigue strength of the joint, $\sigma_{M}[\mathrm{MPa}]$ & 108,202 & 109,850 & 109,850 & 105,577 & 104,790 \\
\hline Amplitude of joint fatigue strength, $\sigma_{A}[\mathrm{MPa}]$ & 88,529 & 89,877 & 89,877 & 86,381 & 85,737 \\
\hline Mean cycle stress of the joint, $\sigma_{m}[\mathrm{MPa}]$ & 30,556 & 30,556 & 30,556 & 30,556 & 30,556 \\
\hline Cycle stress smplitude, $\sigma_{\varepsilon}[\mathrm{MPa}]$ & 25 & 25 & 25 & 25 & 25 \\
\hline Calculated safety degree, $\mathrm{n}_{\mathrm{c}}$ & 3,541 & 3,595 & 3,595 & 3,455 & 3,492 \\
\hline
\end{tabular}


The Soderberg lines for the fatigue design calculations presented in the above tables are shown in the charts from Fig. 9 and Fig. 10.

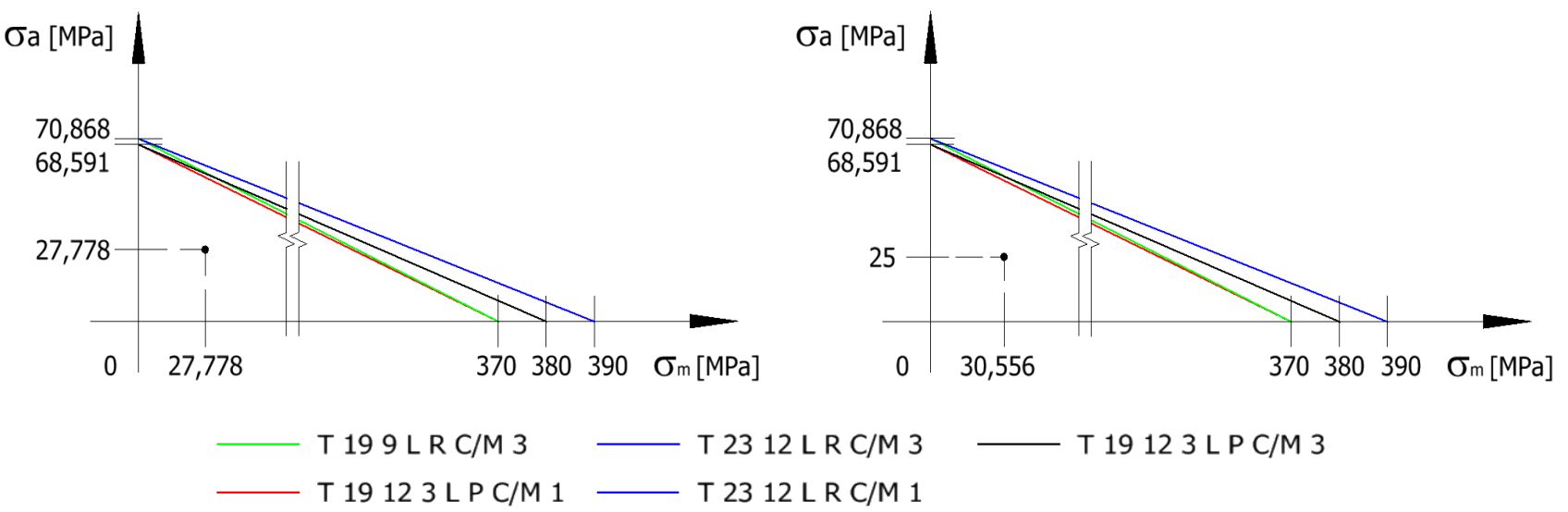

Fig. 9 Soderberg lines for case 1.

Fig. 10 Soderberg lines for case 2.

The results obtained for both fatigue calculations cases indicate design compliance for the considered butt V-weld, when $\mathrm{N}=100000$ cycles. This fact is clearly shown in the graphical representation of the Soderberg's lines, where the point of combined stress is below these lines for all analyzed materials, and where it can also be seen that the material with the lowest fatigue resistance is

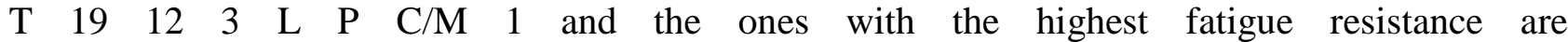
T 2312 L R C/M 3 and T 2312 L R C/M 1.

Due to the fact that for both stress and fatigue calculations the best results were obtained for the T $2312 \mathrm{~L} \mathrm{R} \mathrm{C/M} 3$ and T $2312 \mathrm{~L} \mathrm{R} \mathrm{C/M} 1$ materials, these are the selected welding materials for the physical welded samples. The designed arrangement for the welding layers and the weld joint obtained when T 2312 L R C/M 1 is used are shown in Fig. 11 and Fig. 12.

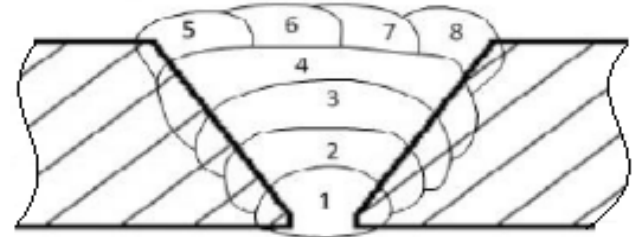

Fig. 11 Designed arrangement of welding layers.

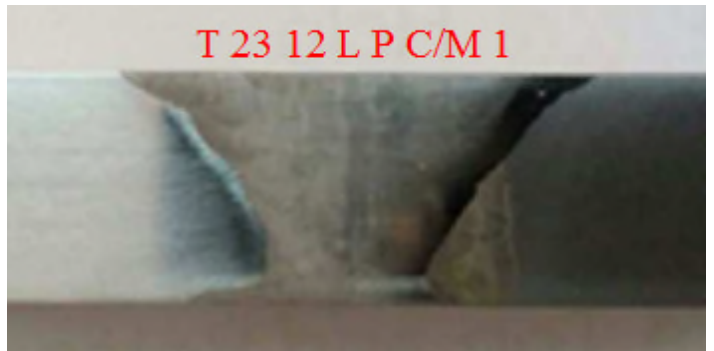

Fig. 12 Obtained weld joint with T 2312 L P C/M 1 welding material.

\section{Summary}

The paper has shown that is a real advantage to use assisted tools in order to select the proper welding material for a specific weld joint from a range of suitable similar materials by means of design stress and fatigue calculations. This alternative can shorten the time to market for a certain product by eliminating the time necessary for physical tests of the weld joint for all suitable materials.

Based on the above analysis and results, the following conclusions can be drawn: the interface of the chosen assisted tool is user friendly and the input of the initial data (material characteristics, weld dimensions, etc.) can be performed with ease; the results show that all materials considered for the 
designed butt V-weld are suitable in accordance with our hypothesis; the materials with the best results and which were used for the weld samples are T $2312 \mathrm{~L} \mathrm{R} \mathrm{C/M} 3$ and T $2312 \mathrm{~L} \mathrm{R} \mathrm{C/M} 1$.

Further research will consists in a physical analysis of the obtained weld joint samples and a comparison of the experimental data with the calculated data.

\section{References}

[1] D. G. Lakatos, M. Bejan, Methods for Determining the Resistance to Fatigue - II, Sci. Eng. 21 (2012) 787-796.

[2] J. D. M. Costa, J. A. M. Ferreira, L. P. M. Abreu, Fatigue behaviour of butt welded joints in a high strength steel, Proc. Eng. 2 (2010) 697-705.

[3] T. Okawa, H. Shimanuki, T. Nose, T. Suzuki, Fatigue Life Prediction of Welded Structures Based on Crack Growth Analysis, Nippon Steel Technical Report, 102 (2013) 51-56.

[4] M. Liljas, C. Ericsson, Fatigue behaviour of stainless steel welds, AvestaPolarit Corr. Manag. Appl. Eng. 1-2 (2002) 2-16.

[5] EWM-Group, Welding Consumables Handbook, forth ed., 2016, available at https://www.ewmgroup.com/en/ewmprodukte/schweisszusatzwerkstoffe.html, accessed: 18.10.2016.

[6] SR EN ISO 17633-A - Welding consumables - Tubular cored electrodes and rods for gas shielded and non-gas shielded metal arc welding of stainless and heat-resisting steels - Classification, 2010.

[7] Autodesk Inventor 2016 Help, Fatigue Curves in Weld Joints (2016). 